\title{
Exploring the Association Between Well-Being and Psychopathology in Adolescents
}

\author{
Meike Bartels • John T. Cacioppo • Toos C. E. M. van \\ Beijsterveldt • Dorret I. Boomsma
}

Received: 12 January 2012/Accepted: 8 February 2013/Published online: 8 March 2013

(C) Springer Science+Business Media New York 2013

\begin{abstract}
Promotion of mental well-being and prevention of emotional and behavioral problems are suggested to go hand in hand. The present study examined the association between subjective well-being (SWB) and psychopathology and investigated the etiology of this association in a large population-based cohort study of adolescent twins $(n=9,136)$ and their non-twin siblings $(n=1,474)$ aged 12-20 years. Phenotypic, genetic, and environmental correlations between SWB and psychopathology were obtained from multivariate genetic modeling conditional on sex. An SWB factor score was used based on measures of subjective happiness, satisfaction with life, and quality of life. Psychopathology was obtained from all syndrome and broad-band scales of the Dutch version of the ASEBA Youth Self Report. Males reported significantly higher levels of SWB than females. Females reported significantly more internalizing problems while males report significantly higher levels of externalizing behavior. In both
\end{abstract}

Edited by Deborah Finkel.

M. Bartels ( $₫)$ - T. C. E. M. van Beijsterveldt · D. I. Boomsma Netherlands Twin Register, Department of Biological Psychology, VU University, Van der Boechorststraat 1, 1081 BT Amsterdam, The Netherlands

e-mail: m.bartels@vu.nl

M. Bartels - T. C. E. M. van Beijsterveldt - D. I. Boomsma EMGO+ Institute for Health and Care Research, VU University Medical Center, Amsterdam, The Netherlands

M. Bartels · D. I. Boomsma

Neuroscience Campus Amsterdam, VU University and VU

Medical Centre, Amsterdam, The Netherlands

J. T. Cacioppo

Department of Psychology, University of Chicago, Chicago, IL, USA sexes, significant negative associations were found between SWB and psychopathology, with the strongest associations seen for SWB and the YSR syndrome scale anxious/depression behavior. The observed associations were primarily explained by genetic correlations while non-shared environmental influences were mainly domain specific. The genetic liability to lower levels of SWB are indicative of a genetic liability to higher levels of psychopathology, suggesting that it might be feasible to screen for emotional and behavioral problems before clear signs are present by screening on indices of subjective wellbeing.

Keywords Well-being - Internalizing · Externalizing · Twin-sibling design $\cdot$ Genetic correlation

There is a growing interest in positive aspects of psychological functioning, especially subjective well-being (SWB) and its possible preventive role for behavioral and emotional problems. Prevention of psychopathology is of increasing urgency given the wide-ranging individual, societal, and economic impact of these disorders (World Health Organization 2004, 2010). In addition, data on SWB may soon be used together with economic data to guide public policy (Stiglitz et al. 2009; Victor 2010). The value of promoting well-being in conjunction with prevention of psychopathology and the public policy implications depend in part on the sources of overlap between SWB and psychopathology.

Not surprisingly, SWB is negatively correlated with psychopathology, especially with depression and mood disorders (e.g. Greenspoon and Saklofske 2010; Proctor et al. 2009) but also with externalizing problems, such as violence, aggression, and substance (ab)use (e.g. MacDonald et al. 2005; Valois et al. 2001). The size of the 
association (correlations generally between -0.40 and -0.55 ) raises the possibility that SWB and psychopathology represent partly distinct dimensions of mental functioning, but also reveal that there is overlap. This has been described in the dual continuum model or the dual-factor mental health model (e.g. Greenspoon and Saklofske 2010; Russell and Carroll 1999; Ryff et al. 2006). Up until recently, only scant attention has been paid to the fact that associations between SWB and psychopathology can be a function of correlated genetic and/or correlated environmental factors.

Individual differences in both SWB and psychopathology have been shown to be partly due to genetic differences between individuals. Estimates of the heritability of SWB tend to hover around $40 \%$, with evidence for presence of additive and non-additive genetic influences (e.g. Bartels and Boomsma 2009; Lykken and Tellegen 1996; Nes et al. 2006; Røysamb et al. 2002, 2003; Stubbe et al. 2005). Combining the results of these studies indicate no difference in heritability estimates between adolescents and adults. In contrast causes of individual differences in psychopathology seem to vary with age. For most behavioral and emotional problems, except for Attention Problems, estimates of the influences of genetic factors vary across development (e.g. Bartels et al. 2007a; Hudziak et al. 2003; Legrand et al. 1999; Kendler et al. 2008; Kan et al. 2012). Changes in the magnitude of genetic influences seem inversely related to changes in the importance of environmental influences shared by children growing up in the same family. Non-shared environmental influences remain more or less constant. Furthermore, longitudinal studies with data from the Netherlands Twin Register indicate that stability of emotional and behavioral problems throughout childhood are mainly accounted for by genetic factors (Bartels et al. 2004, 2007b; Boomsma et al. 2005; Hoekstra et al. 2008; van Beijsterveldt et al. 2003; van Grootheest et al. 2007; Rietveld et al. 2004).

While the heritability estimates of previous studies with a focus on either SWB or psychopathology provide an indication that genetic factors could underlie the association among indices of wellbeing and psychopathology, a large scale study focusing on the underlying sources of covariance between SWB and psychopathology during adolescence is lacking. Two previous studies in adults (Kendler et al. 2011; Nes et al. 2008) explored the relationship between SWB and internalizing psychopathology, including major depression and generalized anxiety disorder. Both studies indicated that genetic factors underlie the phenotypic association between SWB and pscyhopathology of the internalizing subtype. The aim of the current study is to explore whether these observations hold in adolescents and whether they apply both internalizing and externalizing behavioral problems. To this end we conduct a large scale genetically informative study into the sources of overlap between SWB and psychopathology. The large population based sample of adolescent twins and their nontwin siblings allows for estimation of sex-specific phenotypic, genetic, and environmental associations between SWB and psychopathology.

\section{Methods}

\section{Participants}

Participants were registered at birth with the Netherlands Twin Register (NTR) (van Beijsterveldt et al. 2013; Bartels et al. 2007a; Boomsma et al. 2006), established by the Department of Biological Psychology at the VU University in Amsterdam. For the current study, data from surveys collected in adolescent twins and their non-twin siblings were analyzed. The sample consisted of 10,610 individuals $(9,136$ twins and 1,474 non-twin siblings from 5,001 families, $43.7 \%$ males). Mean age of the participants was 16.41 (1.56), with age ranging from 12 to 20 years (born in 1984-1999, 90 \% between 13 and 19 years old). Data from non-twin siblings were included in the analyses with a maximum of 2 siblings ( 1 brother and 1 sister) per family. In families with data for more than one sibling $(n=92)$ and with two siblings of the same sex (49 of the 92 families), the data from sibling closest in age to the twin were selected for analyses. Zygosity was determined for 1210 same-sex twin pairs by DNA polymorphisms. For all other same-sex twin pairs, zygosity was determined by discriminant analysis, using longitudinally assessed questionnaire items from the previously collected parental reports. Agreement between zygosity assignment based on questionnaire information and zygosity determined by DNA markers was around $93 \%$ (Rietveld et al. 2000; Willemsen et al. 2013).

Adolescent twins, and their non-twin siblings (aged 12-25) received a self-report survey. Before inviting twins and their siblings to provide self-report data, parents of twins and siblings $<16$ years of age were contacted to ask for permission to send their children a self-report survey and to register non-twin siblings of the twins. Upon parental consent, questionnaires were sent to the twins and their siblings. Initially, the survey was presented in a paper and pencil version. In 2009 data collection continued with an online version of the questionnaire and the paper and pencil version was used as a second reminder. Response rate was $47 \%$. Non-response analyses showed that parents of twins who did not return the survey have in the past been also less willing to participate in survey research of the YNTR compared to parents of twins that participated. Other parental and familial characteristics, such as SES, 
parental education, religion, and smoking and alcohol consumption during pregnancy were similar for families of non-responding twins compared to families of responding twins. Small, but significant differences were found for externalizing behavior at ages 7 and 12 with nonresponders scoring higher (8.6 vs. 7.4 at age $7 ; 6.5$ vs. 5.0 at age 12). In addition non-responders scored significantly lower on a general test of educational achievement at age 12 , but again the difference is very small (536.4 vs. 538.3). No differences are found for internalizing problems at ages 3,7 , and 12 and externalizing problems at age 3. Furthermore, no differences were found for specific educational achievement tests for language and arithmetic. Total sample constitution and sample constitution as a function of zygosity is described in Table 1.

\section{Measures}

The Dutch Health Behavior Questionnaire (DHBQ) is a self-report instrument containing a broad range of measures on health, lifestyle, and behavior (Bartels et al. 2011). It includes the Youth Self Report (YSR) to assess adolescent psychopathology and three measures of Subjective Well-being. The YSR (Achenbach and Rescorla 2001) is a screening tool for behavioral and emotional problems in adolescents that comprises the Achenbach System of Empirically Based Assessments (ASEBA). Adolescents are asked to fill out 118 items (112 items of the 2001 version supplemented with 6 items from the previous version of the YSR) on a 3-point scale based on the occurrence of the behavior during the preceding 6 months: 0 if the problem item was not true, 1 if it was somewhat or sometimes true, and 2 if it was very true or often true. The eight syndrome scales (AD: anxious/depressed, SC: somatic complaints, WD: withdrawn/depressed, SP: social problems, TP: thought problems, AP: attention problems, RB: rulebreaking behavior, AGG: aggressive behavior) and the broadband scales internalizing problems (INT: anxious/ depressed, somatic complaints and withdrawn/depressed) and externalizing problems (EXT: rule-breaking and aggressive behavior) were based on the 2001 profile (Achenbach and Rescorla 2001). Dutch syndrome scales and comparability with the syndrome scales developed by Achenbach are reported in Verhulst et al. (1997).

Three measures of self-reported evaluations of SWB were used: (1) satisfaction with life (SAT) was assessed with the Satisfaction with Life Scale (Diener et al. 1985). The scale consists of 5 items which had to be answered on a 7-point scale ranging from $1=$ 'strongly disagree' to $7=$ 'strongly agree'. An example items is "My life is going more or less as I wished". Internal consistency of the scale was good with a Chronbach's Alpha of 0.86. (2) Subjective happiness (HAP) was assessed with the Subjective Happiness Scale (Lyubomirsky and Lepper 1999). The scale consists of 4 items which had to be answered on 7-point scale ranging from $1=$ 'strongly disagree' to $7=$ 'strongly agree'. An example items "Compared to most of my peers, I consider myself a happy person". Internal consistency of the scale was good with a Chronbach's Alpha of 0.84. (3) Quality of life in general (QLg) was assessed with the Cantril Ladder (Cantril 1965). The ladder has 10 steps: the top indicates the best possible life, and the bottom the worst possible life. Participants had to indicate the step of the ladder at which they place their lives in general.

Since the data were collected in a unselected population sample some of the measures showed a skewed distribution, which may cause small biases in parameter estimates. However, as transformation of the data does not remove these biases and the bias is known and small (unbiased estimate of the additive genetic effect, underestimation of

Table 1 Sample size and characteristics

\begin{tabular}{llll}
\hline Family constitution & Number of families & Zygosity & Number of families \\
\hline One of the twin, no sibling & 654 & MZM & 551 \\
Twin pair, no sibling & 2,876 & DZM & 476 \\
One of the twin with a brother & 38 & MZF & 792 \\
One of the twin with a sister & 71 & DZF & 571 \\
One of the twin with a brother and a sister & 1 & DOSmf & 576 \\
Twin pair with a brother & 603 & DOSfm & 545 \\
Twin pair with a sister & 707 & In total 5,001 families \\
Brother only (no twin) & 16 & Cohort: 1984-1999 \\
Sister only (no twin) & 33 & Mean age 16.41 (1.56) \\
Brother and sister only (no twin) & 2 &
\end{tabular}

MZM monozygotic males, DZM dizygotic males, $M Z F$ monzygotic females, DZF dizygotic females, DOSmf male-female dizygotic twin pair, DOSfm female-male dizygotic twin pair 
the shared environmental effect, and an overestimation of the unique environmental effect; see Derks et al. 2004) untransformed data were analyzed.

The SWB measures correlate substantially, with correlations in the range of $0.35-0.73$ for males and $0.45-0.77$ for females, indicating a moderate to large overlap between the measures. In our previous work (Bartels and Boomsma 2009) we showed that genetic factors are responsible for the moderate to high phenotypic associations between SAT, HAP, and QLg. Therefore a latent factor score for SWB was estimated for each participant in the dataset. This was done by specifying a factor model with the three observed measures of SWB loading on a single latent factor (SWB) in Mplus (Muthén and Muthén 2010). Given this factor solution and individuals' scores on the observed measures of SWB, a latent factor score can be estimated for each individual. This factor score has a mean of zero and a variance of 1 , with a low score corresponding to low levels of SWB. To overcome problems of a low variance in this SWB factor score, we multiplied the factor score by 10 .

\section{Statistical analyses}

First, a tri-variate genetic model focusing on the overlap between SWB, INT, and EXT was evaluated. Second, to gain more insight into the overlap of SWB with the subscales of the YSR we ran bivariate analyses to disentangle the overlap between SWB and each subscale.

\section{Descriptive statistics}

Sex-differences in mean levels of SWB and psychopathology were tested by mixed-model analyses of variance in SPSS 18, with family as a random factor to account for the within-family dependence of the outcome variables. Significance thresholds for the descriptive was set at 0.05 . A small but significant effect of age on mean levels has been reported for SWB and psychopathology (e.g. Bartels et al. 2011; Bartels and Boomsma 2009; Lamb et al. 2010), so age was included as a fixed effect on the means. Furthermore, in our previous work with an overlapping dataset, no differences between DZ twin and non-twins siblings were observed, so estimates were constrained to be equal.

\section{Genetic modelling}

The different degree of genetic relatedness between monozygotic (MZ), dizygotic (DZ) twin pairs and sibling pairs provides the opportunity to disentangle the phenotypic correlations in additive and non-additive genetic, shared environmental, and nonshared environmental components and to obtain estimates of genetic and environmental correlations. Additive genetic variance
(A) represents the additive effects of alleles over all loci that influence the trait. Non-additive genetic effects (D) comprise interactions between alleles at the same locus (dominance) and will also include effects of interaction among alleles at the different loci (epistasis). Shared environmental variance $(\mathrm{C})$ is the part of the variance that is shared by members of a family which is not explained by genetic relatedness and non-shared environmental variance (E) is the part of the non-genetic variance that is unique to an individual. Phenotypic correlations, twin and twin-sibling correlations, and within person and cross-person crosstrait correlations were estimated using a saturated model in OpenMx (Boker et al. 2011). Next, an ACE model was fitted to the data in order to estimate the underlying sources of variance of SWB and psychopathology and their covariance. First, a tri-variate genetic model (SWB-INTEXT) was fitted to the data with additive genetic, shared environmental and non-shared environmental influences (ACE model), including quantitative sex-differences. It was tested whether the influences of the genes and environment are of different magnitudes in males and females by constraining them to be equal. Next, the significance of the shared environmental component was tested.

For the bivariate genetic analyses, the ACE model was also fitted to the data. Tests for sex-differences in parameter estimates were carried out by restricting the estimates to be equal for males and females and testing if this led to a significant deterioration of fit. Next, we tested the significance of $\mathrm{C}$ separately in males and females.

After establishing the best fitting tri-variate and bivariate models, $95 \%$ confidence intervals were estimated for all parameters. Genetic structural equation modeling in OPENMx was used with the raw-data ML procedure for estimation of parameters. Nested submodels were compared by hierarchic $\chi^{2}$ tests. The $\chi^{2}$ statistic is computed by subtracting $-2 \mathrm{LL}$ (log-likelihood) for a reduced model from that for the full model $\left(\chi^{2}=-2 L_{0}-\left(-2 L_{L}\right)\right)$. This $\chi^{2}$ statistic is distributed with degrees of freedom (df) equal to the difference in the number of parameters estimated in the two models $\left(\Delta \mathrm{df}=\mathrm{df}_{0}-\mathrm{df}_{1}\right)$. If the difference test is significant (threshold for the genetic models $p<0.01$ due to multiple testing) the constraints on the nested model cause a significant deterioration of the model.

\section{Results}

Descriptive statistics

Means and standard deviations of SWB and psychopathology are presented in Table 2 for males and females separately. Males reported significantly higher levels of 
Table 2 Number of individuals, means, and standard deviations for SWB and Psychopathology separately for males and females

\begin{tabular}{|c|c|c|c|c|c|c|}
\hline & \multicolumn{3}{|l|}{ Males } & \multicolumn{3}{|c|}{ Females } \\
\hline & $\mathrm{N}$ & M & $\mathrm{sd}$ & $\mathrm{N}$ & M & sd \\
\hline SWB & 4318 & 0.072 & 0.88 & 5547 & $-0.056^{*}$ & 0.97 \\
\hline Withdrawn (WD) & 4409 & 2.09 & 1.99 & 5723 & $2.62^{*}$ & 2.28 \\
\hline Somatic complaints (SC) & 4386 & 1.76 & 2.02 & 5688 & $3.05^{*}$ & 2.67 \\
\hline Anxious/depressed (AD) & 4390 & 3.06 & 3.43 & 5704 & $5.16^{*}$ & 4.71 \\
\hline Internalizing problems (INT) & 4297 & 6.79 & 5.85 & 5590 & $10.56^{*}$ & 7.88 \\
\hline Rule-breaking behavior (RB) & 4432 & 2.76 & 1.97 & 5746 & $2.46^{*}$ & 1.95 \\
\hline Aggressive behavior (AGG) & 4407 & 6.02 & 4.41 & 5715 & 6.00 & 4.03 \\
\hline Externalizing problems (EXT) & 4405 & 8.79 & 5.74 & 5713 & $8.46^{*}$ & 5.38 \\
\hline Social problems (SP) & 4434 & 2.16 & 1.87 & 5757 & 2.10 & 1.89 \\
\hline Thought problems (TP) & 4426 & 1.62 & 1.75 & 5748 & $1.92^{*}$ & 1.87 \\
\hline Attention problems (AP) & 4419 & 4.63 & 2.77 & 5743 & $4.96^{*}$ & 2.85 \\
\hline
\end{tabular}

SWB subjective well-being

* Females score significantly different than males $(p<0.05)$

Table 3 Phenotypic correlations, twin correlations and cross-twin cross-trait correlations for SWB, INT and EXT

\begin{tabular}{|c|c|c|c|c|c|c|c|c|c|c|c|}
\hline \multicolumn{6}{|c|}{ Males } & \multicolumn{6}{|c|}{ Females } \\
\hline \multicolumn{6}{|c|}{ Phenotypic } & \multicolumn{6}{|c|}{ Phenotypic } \\
\hline \multicolumn{3}{|c|}{ SWB } & INT & & EXT & \multicolumn{3}{|c|}{ SWB } & INT & & EXT \\
\hline SWB & \multicolumn{2}{|l|}{1} & & & & SWB & \multicolumn{2}{|l|}{1} & & & \\
\hline INT & \multicolumn{2}{|l|}{$-0.43(-0.46,-0.41)$} & \multicolumn{3}{|l|}{1} & INT & \multicolumn{2}{|c|}{$-0.58(-0.59,-0.56)$} & \multicolumn{2}{|l|}{1} & \\
\hline EXT & \multicolumn{2}{|c|}{$-0.19(-0.22,-0.16)$} & \multicolumn{2}{|c|}{$0.42(0.39,0.44)$} & 1 & EXT & \multicolumn{2}{|c|}{$-0.30(-0.32,-0.27)$} & \multicolumn{2}{|c|}{$0.47(0.45,0.49)$} & 1 \\
\hline \multicolumn{6}{|l|}{ MZM } & \multicolumn{6}{|l|}{ MZF } \\
\hline \multicolumn{2}{|r|}{ SWB } & INT & & \multicolumn{2}{|c|}{ EXT } & \multicolumn{2}{|r|}{ SWB } & \multicolumn{2}{|l|}{ INT } & \multicolumn{2}{|l|}{ EXT } \\
\hline SWB & \multicolumn{5}{|l|}{$0.33(0.26,0.39)$} & SWB & \multicolumn{3}{|l|}{$0.45(0.40,-0.49)$} & \multirow{3}{*}{\multicolumn{2}{|c|}{$0.61(0.57,0.64)$}} \\
\hline INT & $-0.26(-0.30,-0.21)$ & \multicolumn{2}{|c|}{$0.47(0.41,0.52)$} & \multirow{2}{*}{\multicolumn{2}{|c|}{$0.52(0.46,0.56)$}} & INT & $-0.36(-0.40,-0.32)$ & \multicolumn{2}{|c|}{$0.53(0.48,0.57)$} & & \\
\hline EXT & $-0.15(-0.20,-0.10)$ & 0.23 & $(0.19,0.28)$ & & & EXT & $-0.22(-0.26,-0.18)$ & 0.34 & $30,0.37)$ & & \\
\hline $\mathrm{DZM} / 1$ & nale-male & & & & & $\mathrm{DZF} / \mathrm{fe}$ & male-female & & & & \\
\hline & SWB & INT & & EXT & & & SWB & INT & & EXT & \\
\hline SWB & $0.20(0.14,0.25)$ & & & & & SWB & $0.29(0.23,0.34)$ & & & & \\
\hline INT & $-0.14(-0.18,-0.09)$ & 0.24 & $(0.18,0.30)$ & & & INT & $-0.25(-0.29,-0.20)$ & 0.30 & $24,0.35)$ & & \\
\hline EXT & $-0.10(-0.14,-0.06)$ & 0.14 & $(0.10,0.18)$ & 0.24 & $20,0.28)$ & EXT & $-0.15(-0.19,-0.11)$ & 0.16 & $12,0.20)$ & 0.25 & $0.29)$ \\
\hline $\mathrm{DOS} / \mathrm{n}$ & ale-female & & & & & & & & & & \\
\hline & SWB & & & NT & & EX & XT & & & & \\
\hline SWB & $0.20(0.16,0.24$ & & & & & & & & & & \\
\hline INT & $-0.15(-0.19$ & $-0.12)$ & & $22(0$. & $0.26)$ & & & & & & \\
\hline EXT & $-0.08(-0.10$ & $-0.05)$ & & $09(0$. & $0.12)$ & & $26(0.21,0.30)$ & & & & \\
\hline
\end{tabular}

SWB $(p<0.05)$ than females. Females reported significantly more internalizing problems while males report significantly higher levels of externalizing behavior $(p<0.05)$. The difference in externalizing behavior is based on a significant higher score on rule-breaking behavior for males, while no differences in mean levels were found for aggressive behavior between males and females. 
Tri-variate phenotypic, twin, and cross-twin cross-trait correlations

Phenotypic correlations, twin correlations and cross-twin cross-trait correlations for SWB, INT and EXT are provided in Table 3 . For males phenotypic correlations between SWB and INT and SWB and EXT were -.43 and -0.19 respectively. The phenotypic correlation between INT and EXT is 0.42. For females a similar picture emerges, but the size of all correlation is larger (SWBINT: -0.58; SWB-EXT: -0.30; INT-EXT: 0.47). Twin correlations indicate that familial resemblance is mainly accounted for by additive genetic influences and that nonshared environmental influences account for a large proportion of variance. Cross-twin cross-trait correlations are higher for $\mathrm{MZ}$ than for $\mathrm{DZ}$ twins and twin-sibling relatives, providing evidence for the influence of genetic effects on the association between SWB and psychopathology.

Tri-variate genetic model fitting and variance/ covariance decomposition

Model fitting results for the tri-variate analyses are presented in Table 4 and show that constraining the variance/ covariance components to be equal for males and females gave a significant deterioration in model fit $\left(\chi_{18}^{2}=520.77\right.$, $p=0.00)$. Shared environmental influences could be dropped from the model without a significant deterioration of fit $\left(\chi_{12}^{2}=16.6, p=0.17\right)$. Since the twin-sibling and the cross-twin/sibling correlations provided some evidence for the significance of shared environmental influences for females an $\mathrm{AE}_{\text {males }}-\mathrm{ACE}_{\text {females }}$ models was applied to the data, but this model gave a less parsimonious solution to the data than the AE model.

Table 5 provides the standardized variance/covariance components and their $95 \%$ confidence intervals for SWB, INT, EXT based on the best fitting AE model. Heritability is estimated to be around $34 \%$ for the SWB factor score in males and $47 \%$ in females. For males genetic influences account for 45 and $49 \%$ of the variance in INT and EXT, respectively, and for 53 and $58 \%$ in females. For both males and females the remaining variance is accounted for by non-shared environmental influences.

The off-diagonal estimates provide the percentages of the covariance between SWB and INT and EXT that is accounted for by genetic and non-shared environmental components. For males the main source of covariance constitutes of genetic factors. Notably, the genetic influences on the covariance between SWB and psychopathology (SWB-INT; $58 \%$; SBW-EXT: $86 \%$ ) are larger than the influences of genetic factors on the covariance between INT and EXT (56\%). The remaining influence on the covariance is accounted for by non-shared environmental factors. For females a similar picture emerges. In females

Table 4 Tri-variate model fitting results

\begin{tabular}{lllll}
\hline Model & $-2 L L$ & df & $\chi^{2}$ & df \\
\hline 1, ACE with sex-differences & 194771.2 & 29825 & & \\
2, ACE no sex-differences & 195291.96 & 29843 & 520.77 & 18 \\
3. AE sex differences & $\mathbf{1 9 4 7 8 7 . 8}$ & $\mathbf{2 9 8 3 7}$ & $\mathbf{1 6 . 6}$ & $\mathbf{1 2}$ \\
4. AE males_ACE & 194807.49 & 29831 & 7.41 & $\mathbf{0 . 1 7}$ \\
\hline
\end{tabular}

Note The best fitting model is printed in bold

Table 5 Standardized estimates (95\% CI) for additive genetic and nonshared environmental influences on SWB, INT, EXT and their covariance based on the best fitting model

\begin{tabular}{|c|c|c|c|c|c|c|}
\hline & \multicolumn{3}{|l|}{ A } & \multicolumn{3}{|l|}{$\mathrm{E}$} \\
\hline & SWB & INT & EXT & SWB & INT & EXT \\
\hline \multicolumn{7}{|l|}{ Males } \\
\hline SWB & $0.34(0.28,0.39)$ & & & $0.66(0.61,0.72)$ & & \\
\hline INT & $0.58(0.49,0.67)$ & $0.45(0.40,0.50)$ & & $0.42(0.33,0.51)$ & $0.55(0.50,0.60)$ & \\
\hline EXT & $0.86(0.68,1.06)$ & $0.56(0.47,0.65)$ & $0.49(0.44,0.54)$ & $0.14(-0.06,0.32)$ & $0.44(0.35,0.53)$ & $0.51(0.46,0.56)$ \\
\hline \multicolumn{7}{|c|}{ Females } \\
\hline SWB & $0.47(0.42,0.51)$ & & & $0.53(0.49,0.58)$ & & \\
\hline INT & $0.66(0.60,0.71)$ & $0.53(0.49,0.57)$ & & $0.34(0.29,0.40)$ & $0.47(0.43,0.51)$ & \\
\hline EXT & $0.78(0.68,0.87)$ & $0.72(0.66,0.78)$ & $0.58(0.54,0.62)$ & $0.22(0.13,0.32)$ & $0.28(0.22,0.34)$ & $0.42(0.38,0.46)$ \\
\hline
\end{tabular}


however, the influences of genetic factors is stronger for the association between INT and EXT (72\%) than between SWB and INT (66\%). Remarkably, the estimate of genetic influences on the covariance is highest for the overlap between SWB and EXT (78\%). Confidence intervals for these genetic influences on the covariances are overlapping though in females. Genetic correlations between SWB and INT ( $\widehat{\varsigma}:-0.64 ;$; $:-0.76)$ and EXT ( $\widehat{\circ}$ : -0.40 ; $\odot:-0.45)$ are in the same range for males and females and are stronger for overlap between SWB and INT than SWB and EXT (Table 6). The non-shared environmental correlations are moderate for SWB and INT ( 0 : -0.30 ; ㅇ: -0.40 ), but lower for SWB and EXT ( $\widehat{\circ}:-0.04$; $:-0.14)$. As expected the correlations are negative for the overlap between SWB and psychopathology but positive for the overlap between INT and EXT ( 3 : 0.35 ; + : 0.30 ), indicating that for SWB and psychopathology partly overlapping genes and environmental influences play a role, but with effects in the opposite directions.

Bivariate phenotypic, twin, and cross-twin-cross-trait correlations

To gain more insight in the overlap between SWB and psychopathology we ran bivariate analyses for SWB with each YSR subscale. Phenotypic correlations are depicted in Fig. 1. For males phenotypic correlations ranged from -0.18 to -0.44 . Correlations were stronger (more negative) for internalizing related subscales withdrawn and anxious/ depressed. For females phenotypic correlations ranged from -0.25 to -0.58 , indicating that the overlap between SWB and psychopathology is stronger in females than in males. Twin and cross-twin cross-trait correlations are presented in Table 8 and indicate that the genetic architecture of the overlap between SWB and the psychopathology subscales is largely similar for each scale and for males and females.

Model fitting results are presented in Table 9. The order of model fitting is based on the twin correlations and cross-twin cross-trait correlations. The best fitting model is chosen on the basis of parsimony. In Fig. 1 the underlying sources of the phenotypic correlations are presented. For males the phenotypic correlations are accounted for by genetic and non-shared environmental factors. No significant influences of shared environment on the covariance between SWB and psychopathology were found for males. A similar picture emerged for the females, with the largest part of the phenotypic correlation accounted for by genetic factors.

Genetic and environmental correlations between SWB and psychopathology are reported in Table 7. In males the genetic correlations were much larger than the non-shared environmental correlations, indicating that to a significant extent the same genes influence both constructs. The lower non-shared environmental correlations indicate that environmental influences are more distinct. For females genetic correlations were also strong and non-shared environmental correlations were weaker.

\section{Discussion}

This study obtained several results that bear on the relationship between SWB and psychopathology and are essential to value the role of SWB in psychopathology prevention. First, there were substantial shared genetic influences on SWB and psychopathology, with large correlations for the overlap of SWB with INT than for SWB with EXT. Second, the nonshared environmental influences on SWB and psychopathology were largely unique to each domain. Previous research by Kendler and colleagues (Kendler et al, 2011) focused on internalizing psychopathology and mental well-being in adults and reported a phenotypic correlation of -0.54 of which $86 \%$ was mediated by genetic factors and $14 \%$ by nonshared environmental factors. No quantitative sex-differences were found. Important, the overlap between genetic factors was large while the overlap between environmental factors was

Table 6 Genetic and environmental correlations (95\% CI) for the overlap between SWB, INT, and EXT

\begin{tabular}{|c|c|c|c|c|c|c|}
\hline \multicolumn{4}{|l|}{$r_{g}$} & \multicolumn{3}{|l|}{$\mathrm{r}_{\mathrm{e}}$} \\
\hline & SWB & INT & EXT & SWB & INT & EXT \\
\hline \multicolumn{7}{|l|}{ Males } \\
\hline SWB & 1 & & & 1 & & \\
\hline INT & $-0.64(-0.72,-0.56)$ & 1 & & $-0.30(-0.36,-0.24)$ & 1 & \\
\hline EXT & $-0.40(-0.49,-0.31)$ & $0.50(0.43,0.57)$ & 1 & $-0.04(-0.11,0.02)$ & $0.35(0.29,0.41)$ & 1 \\
\hline \multicolumn{7}{|l|}{ Females } \\
\hline SWB & 1 & & & 1 & & \\
\hline INT & $-0.76(-0.81,-0.71)$ & 1 & & $-0.40(-0.44,-0.35)$ & 1 & \\
\hline EXT & $-0.45(-0.51,-0.38)$ & $0.60(0.55,0.65)$ & 1 & $-0.14(-0.20,-0.08)$ & $0.30(0.25,0.35)$ & 1 \\
\hline
\end{tabular}

Note $r_{g}$ genetic correlation, $r_{e}$ nonshared environmental correlation 
Fig. 1 Phenotypic correlations between SWB and psychopathology and the proportions that are accounted for by genetic and nonshared environmental influences

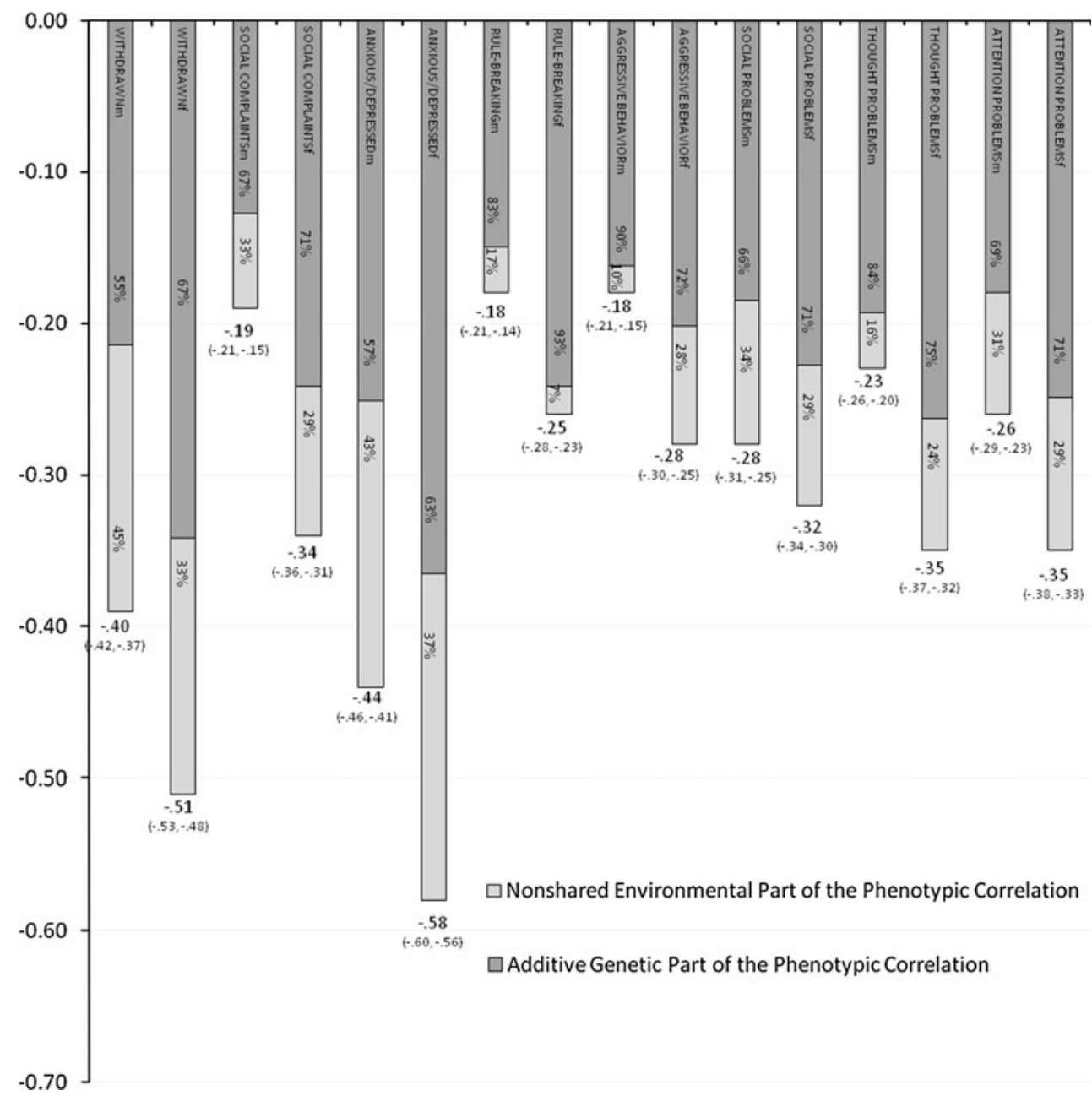

Table 7 Genetic and Environmental Correlations between SWB and psychopathology, with their $95 \%$ confidence intervals

\begin{tabular}{|c|c|c|c|c|}
\hline & \multicolumn{4}{|l|}{ SWB } \\
\hline & \multicolumn{2}{|l|}{ Males } & \multicolumn{2}{|l|}{ Females } \\
\hline & $r_{g}$ & $\mathrm{r}_{\mathrm{e}}$ & $r_{g}$ & $\mathrm{r}_{\mathrm{e}}$ \\
\hline Withdrawn/depressed & $-0.63(-0.72,-0.53)$ & $-0.27(-0.32,-0.21)$ & $-0.74(-0.80,-0.68)$ & $-0.30(-0.36,-0.26)$ \\
\hline Somatic complaints & $-0.36(-0.48,-0.25)$ & $-0.10(-0.16,-0.04)$ & $-0.53(-0.61,-0.46)$ & $-0.18(-0.23,-0.12)$ \\
\hline Anxious/depressed & $-0.67(-0.75,-0.58)$ & $-0.30(-0.35,-0.25)$ & $-0.76(-0.81,-0.72)$ & $-0.42(-0.46,-0.37)$ \\
\hline Rule-breaking behavior & $-0.36(-0.47,-0.26)$ & $-0.05(-0.11,0.01)$ & $-0.47(-0.54,-0.41)$ & $-0.04(-0.09,0.02)$ \\
\hline Aggressive behavior & $-0.38(-0.49,-0.29)$ & $-0.03(-0.09,0.03)$ & $-0.39(-0.46,-0.33)$ & $-0.15(-0.21,-0.10)$ \\
\hline Social problem & $-0.52(-0.62,-0.41)$ & $-0.15(-0.20,-0.09)$ & $-0.50(-0.58,-0.43)$ & $-0.17(-0.22,-0.11)$ \\
\hline Thought problems & $-0.50(-0.60,-0.40)$ & $-0.06(-0.13,0.00)$ & $-0.53(-0.60,-0.47)$ & $-0.17(-0.22,-0.11)$ \\
\hline Attention problems & $-0.47(-0.59,-0.37)$ & $-0.13(-0.19,-0.06)$ & $-0.54(-0.60,-0.47)$ & $-0.20(-0.25,-0.14)$ \\
\hline
\end{tabular}

Note $r_{g}$ genetic correlation, $r_{e}$ nonshared environmental correlation

small. We reported a phenotypic correlation of -0.43 for males $(58 \% \mathrm{~A}$ and $42 \% \mathrm{E})$ and of -0.58 for females $(66 \%$ A, $34 \% \mathrm{E})$. We also found that the overlap between genetic factors is substantial $\left(\hat{o}: r_{\mathrm{g}}=-0.64 ; \circ:-0.76\right)$ in contrast to the overlap in environmental factors $\left({ }^{*}: r_{e}=\right.$ -0.30 ; : : -0.40$)$.

Nes et al. (Nes et al. 2008) also reported sex difference, with genetic factors being the major source of overlap 
between internalizing problems and satisfaction with life in males and shared environment also accounting for overlap in females. The power concern, raised by Nes et al., is covered by our larger sample of twins and additional siblings (Posthuma and Boomsma, 2000).

The unique broad focus of our study with measures of both internalizing as well as externalizing problems and the ability of estimating sex-specific effects provides large added value to field of research on the etiology of the overlap between SWB and psychopathology. The focus on both internalizing as well as externalizing problems reveals that there is also a significant overlap between SWB and externalizing problems, which in both males and females are mainly accounted for by genetic factors.

The finding of the high genetic overlap between SWB and psychopathology is of value in the design and development of new prevention. It indicates that a genetic liability to lower SWB is indicative of a genetic liability to higher psychopathology. The commonality of heritable influences on SWB and psychopathology may lead to the identification of the vulnerable at risk groups prior to any manifestation of psychopathology (Lewinsohn et al. 1991). It could, for example, be suggested that SWB screening can be used as an innovative psychopathology prevention strategy, with the possibility of capturing individuals at risk for the development of psychopathology, before onset of early psychopathological symptoms, based on a low score on SWB.

Since the overlap between psychopathology and SWB is mainly genetic, prevention has to deal with individual differences. This would suggest that population wide launched initiatives to promote SWB need to be reconsidered and probably redesigned to become more tailored for distinct groups of (genetically distinct) individuals to reach its optimal goal. New studies into gene-intervention interaction are highly needed to investigate the effects of genetic differences on intervention effects.

Finally, founded in the field of epidemiology and somatic medicine, it has been proposed that larger benefits to overall public health and mental capital are to be expected when the bell curve of mental health in the human population is shifted a little to the healthy site, the so-called population strategy (Rose, 2008). A relative slight increase in the level of SWB of the bulk of the population, possibly induced by a SWB promotion program, may have a larger preventive effect than targeting the much smaller group of people at high risk. The genetic overlap between SWB and psychopathology, and thus the overlap in vulnerability, makes this theory ground for novel approaches to reduce psychopathology.

While interpreting the results, the following limitation should be kept in mind. We used the Youth Self Report in a normal population sample, resulting in skewed data. Based on the paper by Derks et al. (2004), we decided not to transform the data to approach normality. Use of these skewed data could have resulted in an underestimation of the shared environmental effects and an overestimation of the nonshared environmental effects. We do, however, not expect a large influence on the reported genetic architecture for the overlap between SWB and psychopathology, since SWB is normally distributed. We, furthermore, relied on adolescent self-report data. A multiple rater approach, with for example parental or teacher ratings would have been more reliable (Bartels et al., 2007b), but approaching both the adolescent themselves and their parent would have resulted in a lower response rate and consequently lower power for the current study. Furthermore, in the Dutch school system adolescent do have many teachers at the same time, resulting in the absence of a specific teacher with enough knowledge about the pupil to fulfill the requirement to fill out a teacher report form.

Working with data of a voluntary survey study has the implicit risk of sample selection. In order to check for possible selection on level of psychopathology, we compared our means on the YSR broadband and subscales to those reported in the Dutch manual of the YSR (Verhulst et al. 1997). For some subscale our means are higher (TP and AP), while for the remaining they are slightly lower. It should be noted however that our sample is about eighteen times larger than the community sample.

In conclusion, the relationship between SWB and psychopathology has been identified as being sex-specific and complex, with a large role for shared genetic influences on SWB and psychopathology and more disparate nonshared environmental influences on SWB and psychopathology. As a result of these various forces, SWB and psychopathology cannot be considered as opposing ends of a single mental health continuum. The genetic overlap between SWB and psychopathology justifies the integration of prevention and promotion in the field of Mental Health, as has been suggested by the World Health Organization, however this strategies should be selected and indicated, which could for example be achieved by initial screening on SWB to assess risk for psychopathology.

Acknowledgments Funding was obtained from the following grants: the National Institute on Aging (Grant No. RO1AG033590), The Netherlands Organisation for Scientific Research (NWO): "Spinozapremie" (NWO/SPI 56-464-14192); "Twin-family database for behavior genetics and genomics studies" (NWO 480-04-004); "Genetic and Family influences on Adolescent psychopathology and Wellness" (NWO 463-06-001); "A twin-sib study of adolescent wellness" (NWO-VENI 451-04-034). During part of the data collection and analyses of this manuscript M. Bartels was financially supported by a senior fellowship of the (EMGO+) Institute for Health and Care Research.

\section{Appendix}

See Tables 8 and 9 . 


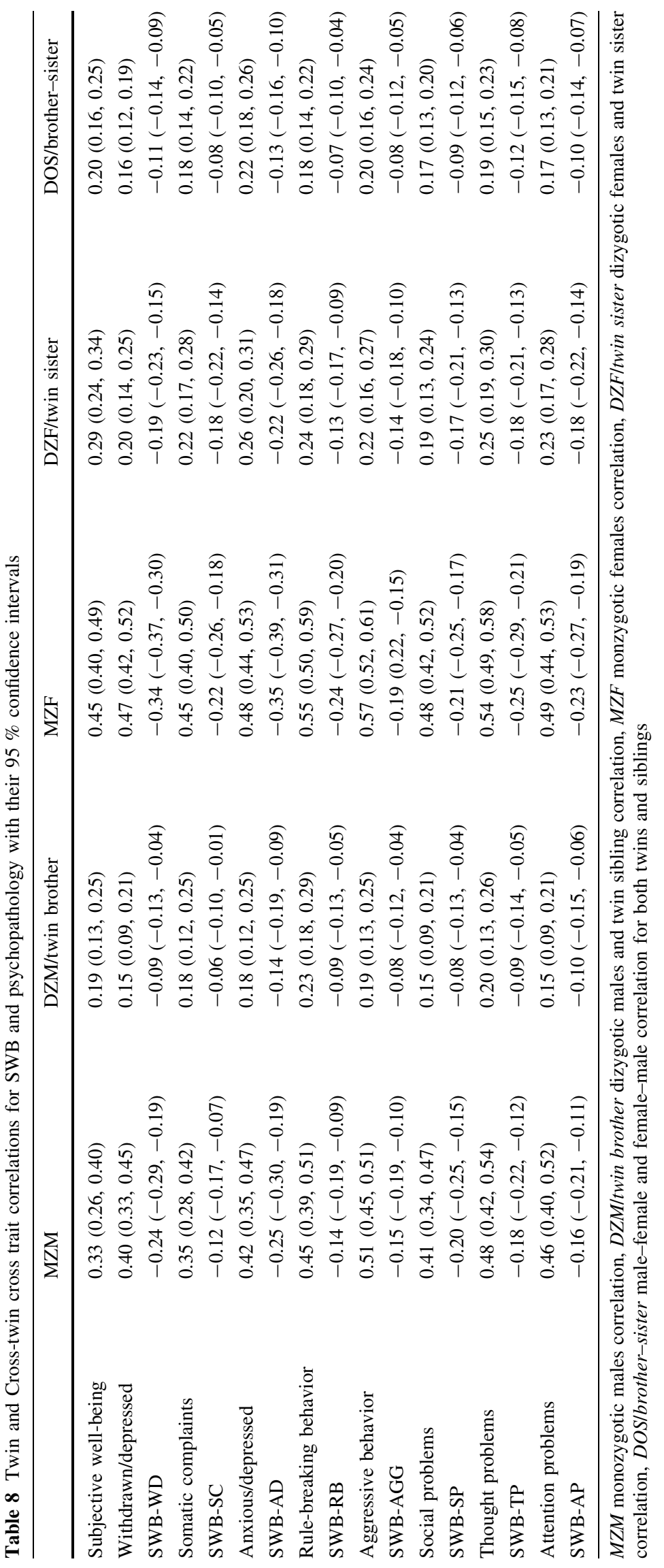




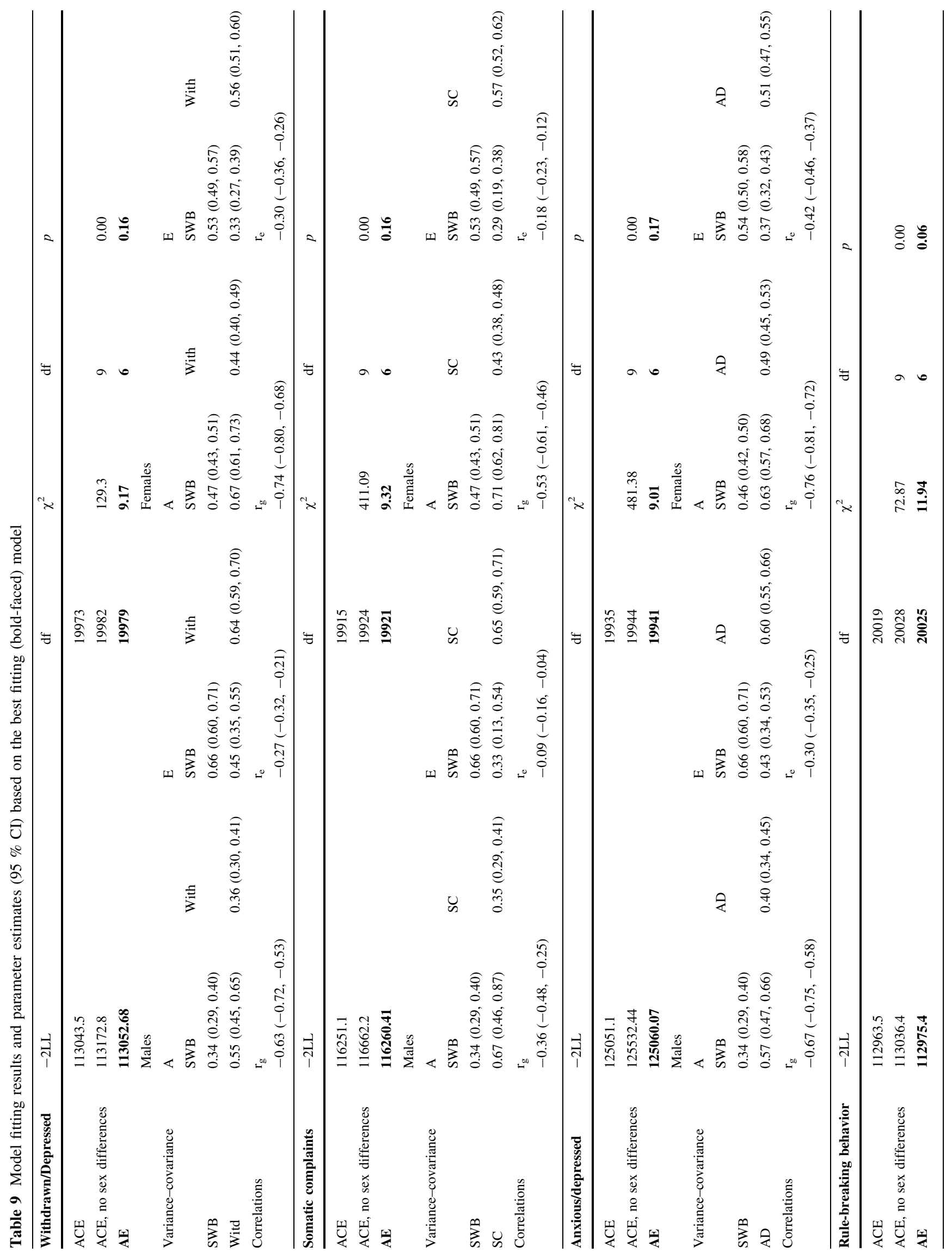




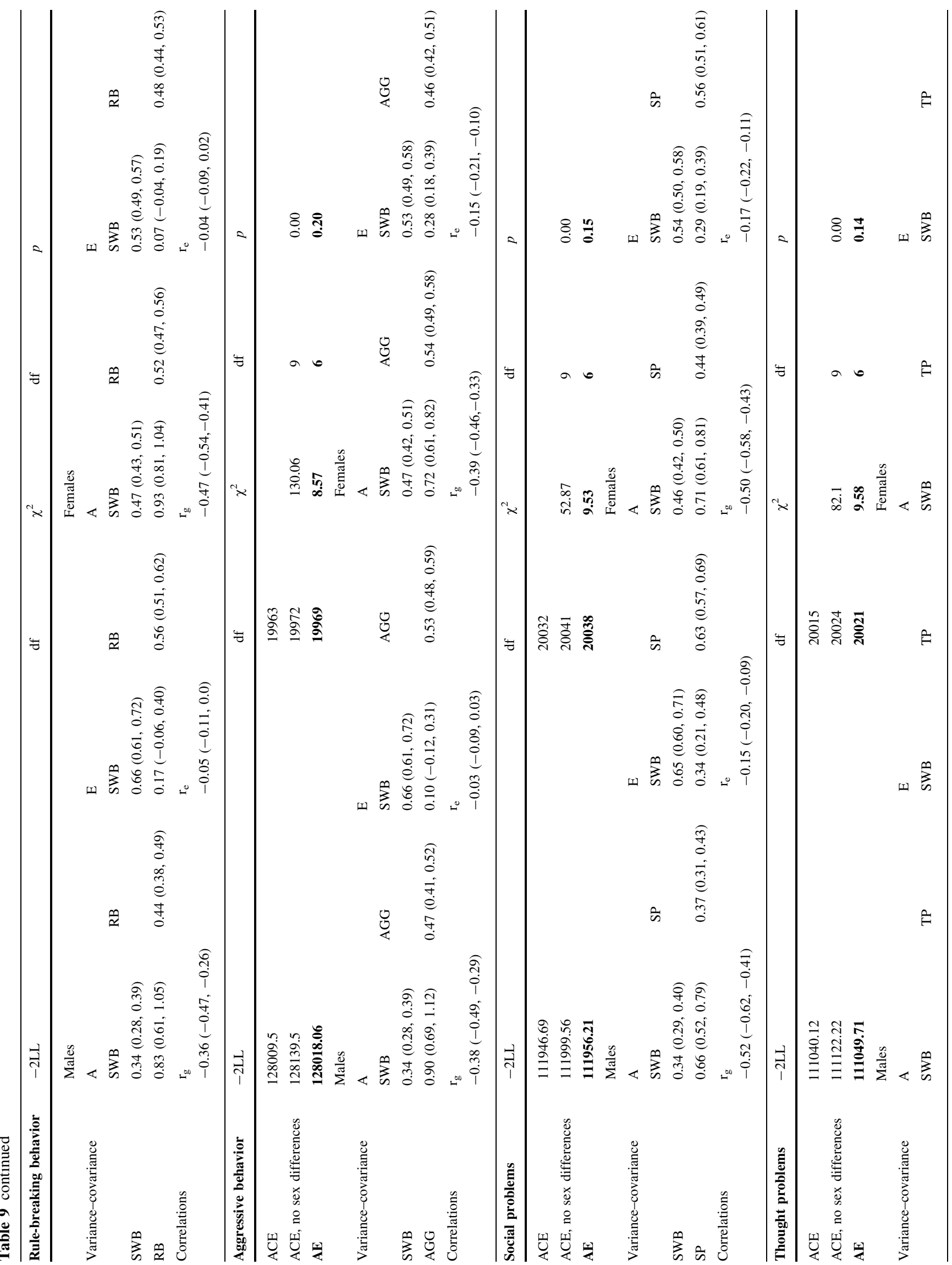




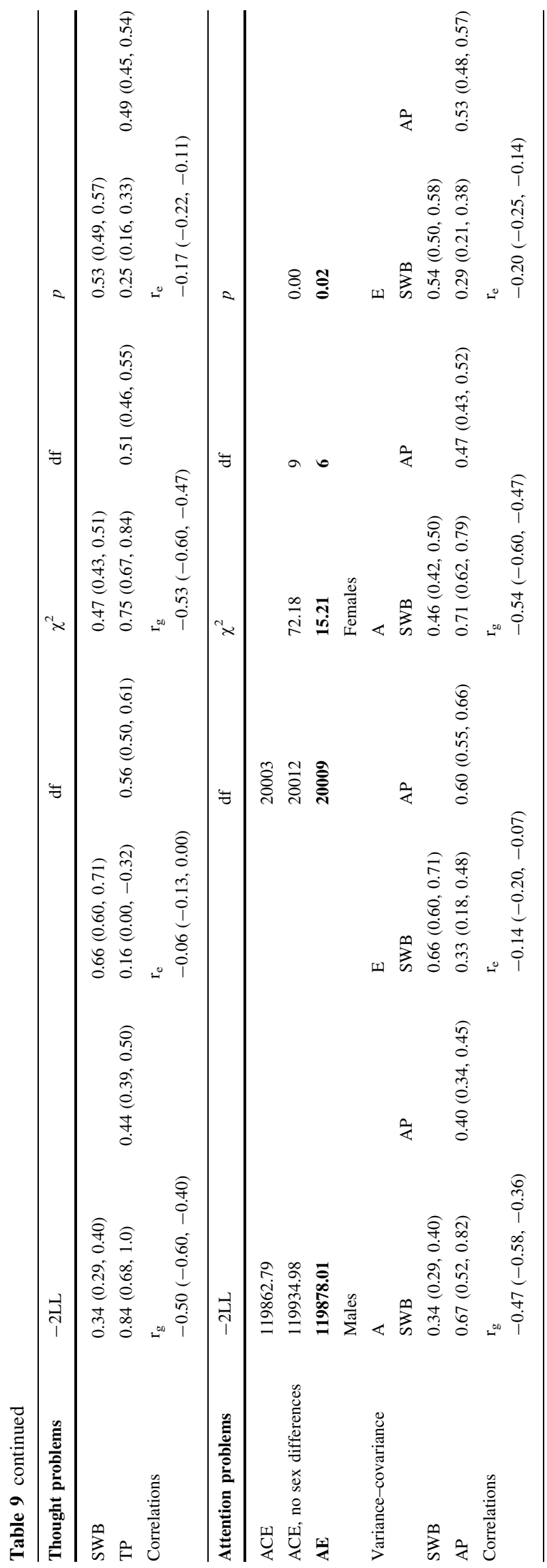

\section{References}

Achenbach TM, Rescorla LA (2001) Manual for the ASEBA schoolage forms \& profiles. University of Vermont, Burlington Department of Psychiatry

Bartels M, Boomsma DI (2009) Born to be happy? The etiology of subjective well-being. Behav Genet 39:605-615

Bartels M, van den Oord EJCG, Hudziak JJ, Rietveld MJH, van Beijsterveldt CEM, Boomsma DI (2004) Genetic and environmental mechanisms underlying stability and change in problem behaviors at ages 3, 7, 10, and 12. Dev Psychol 40(5):852-867

Bartels M, van Beijsterveldt CE, Derks EM, Stroet TM, Polderman TJ, Hudziak JJ, Boomsma DI (2007a) Young Netherlands Twin Register (Y-NTR): a longitudinal multiple informant study of problem behavior. Twin Res Hum Genet 10:3-11

Bartels M, Boomsma DI, Hudziak JJ, van Beijsterveldt CEM, van den Oord EJCG (2007b) Twins and the study of rater (dis)agreement. Psychol Methods 12(4):451-466

Bartels M, van der Aa N, van Beijsterveldt CE, Middeldorp CM, Boomsma DI (2011) Adolescent self-report of emotional and behavioral problems: interactions of genetic factors with sex and age. J Can Acad Child Adolesc Psychiatry 20:35-52

Boker S, Neale M, Maes H, Wilde M, Spiegel M, Brick T, Fox J (2011) OpenMx: an open source extended structural equation modeling framework. Psychometrika 76(2):306-317

Boomsma DI, van Beijsterveldt CE, Hudziak JJ (2005) Genetic and environmental influences on anxious/depression during childhood: a study from the Netherlands Twin Register. Genes Brain Behav 4(8):466-481

Boomsma DI, de Geus EJ, Vink JM, Stubbe JH, Distel MA, Hottenga JJ, Posthuma D, van Beijsterveldt TC, Hudziak JJ, Bartels M, Willemsen G (2006) Netherlands Twin Register: from twins to twin families. Twin Res Hum Genet 9:849-857

Cantril H (1965) The pattern of human concerns. Rutgers University Press, New Brunswick

Derks EM, Dolan CV, Boomsma DI (2004) Effects of censoring on parameter estimates and power in genetic modeling. Twin Res 7(6):659-669

Diener E, Emmons RA, Larsen RJ, Griffin S (1985) The satisfaction with life scale. J Pers Assess 49:71-75

Greenspoon PJ, Saklofske DH (2010) Toward an integration of subjective well-being and psychopathology. Soc Indic Res 54: 81-108

Hoekstra RA, Bartels M, van Beijsterveldt CEM, Boomsma DI (2008) Genetic and environmental influences on the stability of withdrawn behavior in children: a longitudinal, multi-informant twin study. Behav Genet 38(5):447-461

Hudziak JJ, van Beijsterveldt CEM, Bartels M, Derks E, Boomsma DI (2003) Individual differences in aggression in young children: cross-sectional analyses in Dutch twins. Behav Genet 33(5): $575-589$

Kan K-J, Dolan CV, Nivard MG, Middeldorp CM, van Beijsterveldt CEM, Willemsen G, Boomsma DI (2012) Genetic and environmental stability in attention problems across the lifespan: evidence from the Netherlands Twin Register. J Am Acad Child Adolesc Psychiatry 52(1):12-25

Kendler KS, Gardner CO, Lichtenstein P (2008) A developmental twin study of symptoms of anxiety and depression: evidence for genetic innovation and attenuation. Psychol Med 38(11): $1567-1575$

Kendler KS, Myers JM, Maes HH, Keyes CL (2011) The relationship between the genetic and environmental influences on common internalizing psychiatric disorders and mental well-being. Behav Genet 41(5):641-650

Lamb DJ, Middeldorp CM, van Beijsterveldt CE, Bartels M, van der Aa N, Polderman TJ, Boomsma DI (2010) Heritability of 
anxious-depressive and withdrawn behavior: age-related changes during adolescence. J Am Acad Child Adolesc Psychiatry 49: 248-255

Legrand LN, McGue M, Iacono WG (1999) A twin study of state and trait anxiety in childhood and adolescence. J Child Psychol Psychiatry 40(6):953-958

Lewinsohn PM, Rohde P, Seeley JR, Fischer SA (1991) Age and depression: unique and shared effects. Psychol Aging 6:247-260

Lykken D, Tellegen A (1996) Happiness is a stochastic phenomenon. Psychol Sci 7:186-189

Lyubomirsky S, Lepper HS (1999) A measure of subjective happiness: preliminary reliability and construct validation. Soc Indicator Res 46:137-155

MacDonald JM, Piquero AR, Valois RF, Zullig KJ (2005) The relationship between life satisfaction, risk-taking behaviors, and youth violence. J Interpers Violence 20:1495-1518

Muthén LK, Muthén BO (2010) Mplus User's Guide. Muthén \& Muthén, Los Angeles

Nes RB, Røysamb E, Tambs K, Harris JR, Reichborn-Kjennerud T (2006) Subjective well-being: genetic and environmental contributions to stability and change. Psychol Med 36(7):1033-1042

Nes RB, Czajkowski N, Roysamb E, Reichorn-Kjennerud T, Tambs K (2008) Well-being and ill-being: shared environments, shared genes? J Posit Psychol 3:253-265

Posthuma D, Boomsma DI (2000) A note on the statistical power in extended twin designs. Behav Genet 30:147-158

Proctor CL, Linley PA, Maltby J (2009) Youth life satisfaction; a review of the literature. J Happiness Stud 10:583-630

Rietveld MJ, van Der Valk JC, Bongers IL, Stroet TM, Slagboom PE, Boomsma DI (2000) Zygosity diagnosis in young twins by parental report. Twin Res 3:134-141

Rietveld MJH, Hudziak JJ, Bartels M, van Beijsterveldt CEM, Boomsma DI (2004) Heritability of attention problems in children: II. Longitudinal results from a study of twins, age 3 to 12. J Child Psychol Psychiatry 45(3):577-588

Rose G (2008) Rose's strategy of preventive medicine. Oxford University Press, New York

Røysamb E, Harris JR, Magnus P, Vitterso J, Tambs K (2002) Subjective well-being. Sex-specific effects of genetic and environmental factors. Personality Individ Differ 32:211-223

Røysamb E, Tambs K, Reichborn-Kjennerud T, Neale MC, Harris JR (2003) Happiness and health: environmental and genetic contributions to the relationship between subjective well-being, perceived health, and somatic illness. J Pers Soc Psychol 85:1136-1146

Russell JA, Carroll JM (1999) On the bipolarity of positive and negative affect. Psychol Bull 125:3-30
Ryff CD, Dienberg LG, Urry HL, Muller D, Rosenkranz MA, Friedman EM, Davidson RJ, Singer B (2006) Psychological well-being and ill-being: do they have distinct or mirrored biological correlates? Psychother Psychosom 75:85-95

Stiglitz JE, Sen A, Fitoussi JP (2009) Report of the commission on the measurement of economic performance and social progress. OECD Publishing, Paris

Stubbe JH, Posthuma D, Boomsma DI, Geus de EJC (2005) Heritability of life satisfaction in adults: a twin-family study. Psychol Med 35:1581-1588

Valois RF, Zullig KJ, Huebner ES, Drane JW (2001) Relationship between life satisfaction and violent behaviors among adolescents. Am J Health Behav 25:353-366

van Beijsterveldt CEM, Bartels M, Hudziak JJ, Boomsma DI (2003) Causes of stability in childhood aggression: longitudinal genetic analyses in Dutch twins. Behav Genet 33(5):591-605

van Beijsterveldt CE, Groen-Blokhuis M, Hottenga JJ, Franić S, Hudziak JJ, Lamb D, Huppertz C, de Zeeuw E, Nivard M, Schutte N, Swagerman S, Glasner T, van Fulpen M, Brouwer C, Stroet T, Nowotny D, Ehli EA, Davies GE, Scheet P, Orlebeke JF, Kan KJ, Smit D, Dolan CV, Middeldorp CM, de Geus EJC, Bartels M, Boomsma DI (2013) The Young Netherlands Twin Register (YNTR): longitudinal twin and family studies in over 70,000 children. Twin Res Hum Genet 16(1):252-267

van Grootheest DS, Bartels M, Cath DC, Beekman AT, Hudziak JJ, Boomsma DI (2007) Longitudinal genetic and environmental contributions to childhood obsessive-compulsive behavior. Biol Psychiatry 61:308-315

Verhulst FC, van der Ende J, Koot HM (1997) Handleiding voor de Youth Self-Report (YSR) [Manual for the Youth Self-Report (YSR)]. Afdeling Kinder- en Jeugd Psychiatrie, Sophia Kinderziekenhuis/Academisch Ziekenhuis Rotterdam/Erasmus Universiteit Rotterdam, Rotterdam

Victor P (2010) Questioning economic growth. Nature 468:370-371 Willemsen G, Vink JM, Abdellaoui A, den Braber A, van Beek JH, Draisma HH, van Dongen J, Van't Ent D, Geels LM, van Lien R, Ligthart L, Kattenberg M, Mbarek H, de Moor MH, Neijts M, Pool R, Stroo N, Kluft C, Suchiman HE, Slagboom PE, de Geus EJ, Boomsma DI (2013) The Adult Netherlands Twin Register: 25 years of survey and biological data collection. Twin Res Hum Genet 16(1):271-281

World Health Organization (2004). Prevention of mental disorders: effective interventions and policy opinions

World Health Organization (2010). Mental health: strengthening our response; Fact sheet $\mathrm{N}^{\circ} 220$ 